\title{
La construcción de la diferencia: los latinoamericanos
}

\author{
Dolores Juliano
}

Universitat de Barcelona. Facultat de Geografia i Històra

Baldiri i Reixach, s/n. 08034 Barcelona. Spain

\section{Resumen}

A todos los grupos subalternos se les ofrece la misma falsa disyuntiva: integrarse en la cultura dominante, transformándose en malas copias, o mantener su especificidad al precio de la desvalorización. Esto es inevitable si no se cuestiona la premisa mayor implícita: la validez más elevada de los logros culturales de la sociedad receptora. Así el relativismo puede utilizarse para justiftcar la creación de compartimentos estancos en que cada sector quede encerrado en su especificidad. Pero la discriminación puede manifestarse también contra personas con formas de vida muy semejanzes. En España, el problema de la inclusión/exclusion es interesante en el caso de los latinoamericanos, dado que no presentan diferencias considerables (religtosas, de clases sociales, raciales, lingüísticas o educacionales) con la sociedad receptora. Al faltar los elementos a partir de los cuales se unaturalizan la idea de exclusión, queda al descubierto la construcción social de los límites. El antecedente se encuentra en la conceprualización del "indiano" durante el siglo pasado, mediante el cual se "extranjerizaba" a nativos. Este mecanismo de exclusión incrementa su poder de segregación cuando se aplica a los retornados de segunda generación. En las últimas décadas el neologismo "sudacan señala la condición de extranjería social de ese sector. Los límires se activan o se neutralizan en la interacción social y, por consiguiente, en la escuela.

Palabras clave: discriminación, etricidad, relativismo cultural, asimilacionismo.

\section{Abstract. Building difference: the latin-americans}

For all subordinate group it's possible to offer a false disyuntive: integration (changing ir self in bad copy) or to keep specific but discriminated. It is imposible to avoid this option if there is no refuse of the main implicit premise: the tacit agreement that the way of life of the dominant group is morally superior to that of the lowly. We can use the relativism to create closed compartiments, in what everyone remain in your specificity. But discrimination can also be used against very alike people. In Spain is interesant to know the mechanism of inclusion/exclusion for the "latin-americans" subjects. They haven't differences, we can find here the social construction of boundary. I found the preceding during the last half of the mineteenth century: the concept undianon made foreigns the natives. This is so for the second generation of retourned. In the last time, the neologism "sudacas" point the social foreign situation for this group. The bounduries can are either actived or neutralized in social interaction and, of course, in the school.

Key words: discrimination, etnicity, cultural relativism, assimilationism. 


\section{Sumario}

Integración o guetisación: el falso dilema

La escuela ante el dilema

Construyendo diferentes: los sudacas

Bibliografía citada

\section{Integración o guetisación: el falso dilema}

Con cierta frecuencia se engloban bajo un mismo rótulo conductas que tienen poco en común y que incluso pueden ser opuestas, esto es lo que pasa con los prejuicios discriminatorios hacia aquellos que se ven como diferentes. Segregarlos o asimitarlos son dos respuestas que implican valoración negativa de su especificidad (real o asignada), pero parten de marcos teóricos diferentes y tienen también consecuencias diferentes. Ya en la década de los años cincuenta, Oracy Nogueira sistematizó las diferencias entre lo que el llamaba upreconceito de origen" y "preconceito de marca". El primero consideraba las diferencias esenciales $e$ insalvables, ponía barreras a las interrelaciones y toleraba mejor a las minorías cuanto más endógenas y aisladas eran éstas. Se corresponde con las conductas denominadas "racistas" y con el actual "fundamentalismo cultural». El segundo tipo de prejuicio considera que las diferencias son negativas pero modificables, y se pueden ir superando a medida que los otros reciben nuestra influencia. Tolera mejor las minorías más «modernizadas" y abiertas al exterior y se corresponde con conductas asimilacionistas.

Los dos cuernos del dilema reducen las opciones a un modelo de convivencia empobrecido: segregar o asimilar. En ambos casos los europeos nos constituimos en modelo universal (inalcanzable u obligado) de las conductas de los restantes seres humanos. Esta es, sin embargo, una opción falsa, apoyada la primera en strpuestos funcionalistas (el que las sociedades son diferentes y estáticas) y la segunda en el evolucionismo unilineal, que actualmente tiende a confundirse con el universalismo, según el cual toda la diferencia de logros humanos confluyen en un resultado superior y único: nuestra ctiltura occidental.

A partir de estos supuestos, a todos los grupos subalternos se les ofrece la misma falsa disyuntiva: integrarse en la cultura dominante, transformándose en malas copias de los sectores dominantes, o mantener su especificidad al precio de la desvalorización. Las respuestas a esta doble presión han sido variadas. Las mujeres, que constituyen uno de los sectores con más dinamismo político en la actualidad, han oscilado en sus opciones al respecto. Así, en algunas épocas ha predominado un feminismo de la igualdad, caracterizado por reclamar iguales derechos a partir de reivindicar semejantes características de base (tendencia que podría estar representada por Simone de Beauvoir), mientras que en orros momentos ha predominado el feminismo de la diferencia, que subraya la especificidad de las maneras femeninas de ver y sentir el mundo. Las minorias étnicas parecen recorrer el camino inverso: partir de la reivindicación de su derecho a la diferencia para terminar reclamando igualdad de condiciones. 
El dilema parece irresoltuble y lo es si no se cuestiona la premisa mayor implícita: la mayor validez de los logros culturales de los sectores dominantes, que legitiman la acumulación en sus manos de los resortes de poder político y económico.

Ya hace cincuenta años Ruth Benedict constataba que a los integrantes de la cultura occidental les costaba más que a cualquier otro pueblo aceptar la validez de propuestas culturales diferentes, ella decía en su libro clásico:

Aún pueblos muy primitivos tienen a veces más conciencia que nosotros del papel de los tasgos culturales, y con buenas razones. Han tenido la experiencia intima de culturas diferentes. Ante el hombre blanco han visto desaparecer su religión, su sistema económico, sus prohibiciones matrimoniales... El hombre blanco ha tenido una experiencia diferente. Quizá nunca haya visto a un extraño antes que el extraño se hubiera ya europeizado. Conoce poco de los modos de vida ajenos al suyo. La uniformidad de la costumbre, de la perspectiva que ve extenderse a su alrededor le parece bastante convincente aunque en verdad esconde ante él un accidente histórico. Acepta sin mayor dificultad Ia equivalencia entre la naturaleza humana y sus propias modalidades culturales (12-13).

Aceptar la validez equivalente de las diferentes concreciones culturales fue el logro teórico del relativismo cultural, y aún en la actualidad algunos autores, como Camilleri, stugieren que éste ha sido el mayor aporte de la antropologia a la convivencia entre los seres humanos. Desgraciadamente, la ciencia sólo produce discursos, y éstos pueden ser leídos y utilizados de diferentes maneras. El viejo relativismo habla de valores equivalentes, pero en una sociedad desigualitaria, la idea de culturas con valores diferentes y estáticos que deben ser respetados puede utilizarse, $y$ de hecho lo ha sido sistemáticamente, para justificar la creación de compartimentos estancos en que cada sector quede encerrado en su especificidad. La equivalencia cultural queda entonces enredada en la jerarquización social, que dispone de grados de poder y posibilidades de acción muy diversas para los distintos sectores que la integran. Quizá la mayor ironía de nuestra época es, precisamente, que el humanismo relativista haya sido usado para legitimar los más feroces sistemas segregacionistas, como el apartheid sudafricano. Ya lo consignaba Bastide: el principal argumento de la segregación es afirmar que con este sistema se evita que mueran dos culturas, la de los blancos y la de los bantúes.

Aunque es evidente que todo discurso puede ser manipulado, esto no evita el trabajo de analizar a través de qué grietas del bienintencionado relativismo se cuela tan fácilmente el segregacionismo. La transferencia es posible porque el concepto de cultura que manejaban los funcionalistas era un supuesto estático y consensuado, cuya garantía de legitimidad estaba dada por su estabilidad. Estos supuestos son perfectamente aceptables por los discriminadores, que pueden así defender la permanencia de situaciones socialmente asimétricas, justificándolas por lo que representan de respeto a los condicionantes culturales, vistos como inmutables. Este tipo de culturalismo entonces toma 
el relevo del viejo racismo en dos aspectos significativos: considerar a cada persona predestinada por su origen a cierto tipo de conductas y considerar que éstas se mantienen permanentes a través de varias generaciones. Las divergencias son comparativamente menos significativas. Para los racistas estas conductas estaban ligadas al fenotipo y podían incluirse dentro de una escala de valores decrecientes. Para los culturalistas «el problema no es el color de la piel, sino la incompatibilidad culturaln igualmente reificada, y se salva la buena conciencia con un reconocimiento genérico de la equivalencia de las prácticas diferentes (que no implica más aceptación que el: «allá ellos»). El culturalismo además ha tomado los espacios que el racismo en retirada ha ido dejando libre, fundamentalmente como base teórica de las conductas xenófobas ligadas a los nuevos nacionalismos ${ }^{1}$. El mito de la superioridad racial del propio grupo ha sido reemplazado entonces por el de la inmutabilidad de la especificidad cultural. Este se ha demostrado poliforme. Las minorías étnicas dentro de los macroestados, las nacionalidades tradicionales y los estados mismos, pueden recurrir a su argumentación para diseñar políticas excluyentes con respecto a sectores catalogados como distintos o realmente partícipes de culturas diferentes.

Además este discurso se ve como legítimo, pues se apoya en una vertiente de la antropología, y moralmente válido, pues pretende respetar las características esenciales de los demás al mismo tiempo que salvaguarda las propias. $\mathrm{Su}$ eficacia legitimadora de la discriminación es entonces tan alta, que no debe extrañarnos que sea compartido por los medios de comunicación y por los sectores sociales encargados de la autorreproducción social, por ejemplo los maestros.

Como reacción a esta distorsión, algunos antropólogos como Llobera, o sociólogos como Gosselin, acusan al relativismo de causar problemas epistemológicos en la comprensión de los demás (presentando a las diferentes culturas como mundos mutuamente incomunicables) y de producir conflictos sociales (defendiendo el derecho a la diferencia). Pero reconocer que aún en el seno de las macroculturas puede haber sectores que se autoidentifiquen a partir deI subrayado de algunas especificidades, no implica negar la base común (y por consiguiente la inteligibilidad mutua de las concreciones humanas). Además, la jerarquización social existe dentro y fuera del discurso que la describe, y no puede identificarse a priori diferencia (real o construida) con discriminación. Es cierto que hasta ahora no ha existido diferencia sin jerarquización. Lo que no resulta tan evidente es que para suprimir un término de la ecuación haya que suprimir el otro, o que suprimiendo la diferencia se acabe con la jerarquización. De hecho, nuestra sociedad marcha a grandes pasos hacia niveles cada vez más grandes de desigualdad económica, en y entre sociedades cada vez más homogéneas culturalmente. Esto ha sido denunciado reiteradamente y en los últimos meses ha dado pie a un interesante debate entre Petras y

1. Pujadas matiza que la pretensión racista es integrar al diferente dentro de una jerarquización desfavorable, mientras que la opción xenófoba es excluyente. 
Colombres. La propuesta entonces de culpar a las diferencias culturales (reales o asignadas) de la jerarquización social no se apoya en la realidad. La especificidad étrica no es un conjunto de contenidos, sino una red de interrelaciones que sirven de protección algunas veces y de jaula otras. A través de ellas se expresan conflictos de otros tipos, que se reifican y esencializan. Unificar las conductas no significa dar ningún paso en el sentido de la solución de ese problema. Experimentos desarrollados en el aula muestran que se pueden inducir conductas discriminativas a partir de diferencias inexistentes ${ }^{2}$. De hecho los "pogrom" se han realizado habitualmente sobre comunidades, como la judfa, muy integradas en la economía y en la sociedad del país discriminador, y tan semejantes físicamente que obligaba a los racistas a identificar a sus víctimas por símbolos externos (como la estrella de David llevada en lugar visible). Si se quiere unificar la sociedad haciéndola compartir pautas culturales homogéneas, eso no garantiza el cese de la discriminación. Esta se da a partir de la competencia por recursos económicos y ámbitos de poder y puede manifestarse ferozmente contra personas con formas de vida muy semejantes, simplemente rotulándolas legalmente como extranjeros o encasillándolos como "otros" a partir de cualquier particularidad de su sistema de creencias o de su manera de hablar. Es difícil imaginar hasta donde tendría que llegar la uniformización para que no dejara ningún resquicio a una rotulación diferencial. Como muestra el ejemplo escolar, hasta un lazo de color diferente puede ser considerado una diferencia insalvable, si así conviene a la estrategia de poder. Hay que cambiar entonces la base del planteamiento. No es la existencia de la multiculturafidad en una sociedad la que produce los fenómenos de discriminación y los enfrentamientos armados de "limpieza étnica», la otra opción posible es la aceptación y el diálogo.

Esto no impide que el rótulo de "multiculturalidad" y de defensa de la diferencia (o del derecho a ser diferentes) lo puedan utilizar proyectos políticos diferentes. Es evidente que la nueva derecha, en su afán de mantener o ampliar sus ámbitos de poder, aplica la política de dividir para vencer (o separar para discriminar) como lo ha destacado Verena Stolcke. Pero hay también una corriente dentro de las ciencias sociales que presta atención, desde una perspectiva solidaria, a los reclamos de los sectores que se reivindican diferentes: mujeres, minorías étrnicas y jóvenes. De esta corriente forman parte Petras, Ricouer, Gros, La Sociedad Brasileña de Antropología y muchas otras instituciones profesionales e investigadores. Utilizar el mismo rótulo para ambos proyectos es una prestidigitación terminológica. Parece más útil intentar diseñar una taxonomía más precisa. Como señala Petras, el proyecto de creciente control de los

2. Un documental de televisión muestra cómo en una clase de niños la maestra formó dos grupos al azar, asignándole a cada uno lazos de color diferente. Luego comenzó a discriminar ostensiblemente a los que litevaban un color determinado, al poco tiempo muchos nifios de los colocados en el grupo privilegiado comenzaron a cteet legitima la discriminación y a reproducirla en los compañeros que tenian lazos de un color distinto al suyo. Al cambiar el sentido de la discriminación se teprodujo el fenómeno. 
individuos y de los puebios llevado a cabo por los sectores "modernizantes" exige ser complementado por una manipulación intelectual, según la cual la creciente desigualdad social se oculta bajo un discurso de respeto de los derechos humanos, al tiempo que se descartan las propuestas alternativas como utópicas o reaccionarias.

Según las interpretaciones esencialistas, cada grupo humano resultaría portador de determinados contenidos culturales que lo diferencian de los demás grupos y que constituyen su "legado" a transmitir a las nuevas generaciones y la base a partir de la cual se reivindica la pertenencia étnica. La prioridad dada a los contenidos culturales sobre las estructuras sociales en este tipo de aproximación justifica que algunos autores como Siffredi y Briones de Lanata la denominen "contendista". En la actualidad esta línea de investigaciones ha sido reemplazada por modelos transaccionales más dinámicos, de base interaccionista y constructivista, que subrayan la variabilidad de los contenidos, la arbitrariedad de su selección y las estrategias dinámicas a partir de las cuales se definen, aceptan o rechazan las pertenencias étnicas.

Así, la alternativa no está entre un relativismo extremo y un universalismo igualmente excluyente, que es en la práctica un relativismo absolutizado. También se puede partir de la idea de la identidad básica de los seres humanos, y a través del reconocimiento de su dinamismo cultural y de la variedad y fluidez de sus logros, proponer la igualdad de sus derechos y el respeto por sus particularidades.

Si se parte de entender la cultura como un conjunto de estrategias adaptativas, desarrolladas por un grupo humano a través de la historia, como parte de sus interrelaciones con las otras sociedades y con el entorno; se puede aceptar que constituye una configuración dinámica en la que se apoyan las conductas individuales, pero que no las determina. Con este punto de partida se puede otorgar valor positivo a los elementos dinámicos de cada sociedad y a los agentes de cambio cultural, entendidos como actores que facilitan el desarrollo social y no como elementos de su desintegración. Así, el respeto por la diferencia cultural se transforma en interés por las interrelaciones mutuas -y mutuamente enriquecedoras- dejando de lado todo esencialismo. Una interpretación teórica de este tipo brinda un marco más flexible a las relaciones entre minorías y sociedad global, y permite encuadrar mejor la actividad docente con respecto a ambos sectores.

\section{La escuela ante el dilema}

Estudios realizados en las escuelas en Francia (Pierre Jordan) y en Argentina (María Rosa Neufeld) señalan que en ambas sociedades (y probablemente en muchas otras) el discurso del relativismo cultural ha arraigado fuertemente entre los maestros de todos los niveles de enseñanza, que explican a través de él las dificultades escolares de los nifinos de las minorías o sus problemas de integración: los niños "son asín porque vienen de culturas diferentes y la acción de las escuela no puede, ni debe, modificar esa especificidad (aunque en la 
mayoría de los casos implique marginación). La construcción docente respecto a las minorías étnicas, es entonces parte de la construcción social al respecto y se nutre de los aportes del funcionalismo antropológico.

Con anterioridad y en contraposición con la propuesta del relativismo culturalista (a la que algunos autores identifican erróneamente con el multiculturalismo actual) se ha desarrollado desde fines del siglo pasado la propuesta asimilatoria. Esta consiste en igualar las oportunidades de los integrantes de las minorías brindándoles los elementos de conductas y de conocimientos propios de la cultura dominante. Pese a que el miedo a la segregación empuje a docentes bienintencionados y a algunos miembros de las minorías estigmatizadas a este tipo de opción, es evidente que su presunto "universalismo" no significa un paso adelante, sino un retroceso con respecto al relativismo. También en este caso hay un fundamento teórico aparentemente aceptable: la unidad de la especie humana y la existencia de valores y derechos universales, y existe también un colectivo científico que da la base teórica para la propuesta. En este caso se trata de los filósofos, alguno de los cuales, como Finkielkraut o Bueno, acusan duramente a la antropología de fraccionar al mundo en tribus incompatibles y al relativismo de fomentar las guerras civiles de los países del Este.

Desgraciadamente, ni el universalismo que señala "todos somos iguales" ni el relativismo que proclama "todos tenemos derecho a ser diferentes" evitan la realidad de la existencia de un mundo fuertemente jerarquizado, en que algunas sociedades dominan política y económicamente a otras. Encontrar las palabras exactas no cambia esta realidad, pero discursos mal construidos ayudan a legitimarla. La lucha no tiene tampoco que darse entre antropólogos y filósofos, sino entre concepciones estáticas y dinámicas de la sociedad.

\section{Construyendo diferentes: los sudacas}

En España, país de adscripción por nacimiento, el problema de la inclusion/exclusión es particularmente interesante en el caso de los latinoamericanos, dado que no presentan grandes diferencias raciales ni en términos de códigos lingüísticos con la sociedad receptora. Tampoco se encuentran entre los dos grupos diferencias religiosas, ni distancias insalvables en términos de clases sociales, por lo que faitan algunos de los elementos a partir de los cuales se "naturaliza" la idea de exclusión. Esto hace que las prácticas sociales y legales con respecto a los inmigrantes latinoamericanos se presenten como cruciales, desde el punto de vista teórico, para entender el proceso de construcción de la "otredad". Desde el punto de vista legal, si bien existe una contradicción entre el proyecto político de construir una Hispanoamérica integrada y la conceptualización de los latinoamericanos como extranjeros, esto se salva en la práctica otorgando algunas ventajas legales a la inmigración de este origen: menor plazo de residencia para obtener la nacionalidad y más fácil reconocimiento de equivalencias en los estudios. A todos los demás efectos se mantiene la ideología del estado nación como marco de pertenencia legítimo, y se ignoran las semejanzas culturales, tan subrayadas en el discurso político. 
Reviste mayor interés analizar la construcción social, ya que ésta se apoya en una tradición previa a la inmigración que nos octupa. Al respecto, ya en el siglo XVII, el sabio mexicano Siguienza y Góngora se quejaba de la extranjerización y desdén etnocéntrico de que eran objeto los criollos:

Piensan en algunas partes de Europa [...] que no sólo los indios habitadores de estos paises, sino que los de padres espańoles casualmente nacidos en ellos, o andamos en dos pies por divina dispensación, o que, aún valiéndose de microscopios ingleses, apenas se descubre en nosotros lo racional (citado en Galviz, 1982).

Pero el antecedente teórico más significativo se relaciona con la construcción social del uindiano" durante el siglo pasado. Según esta conceptualización popular, cualquier nativo que abandonara temporalmente su pueblo de origen e hiciera fortuna en América, volvía transubstanciado en otra cosa, se "extranjerizaba". A este extranjero construido no se le asignaba más mérito que la riqueza (que era la que le autorizaba a volver). Todos los demás elementos de distancia cultural que le habían proporcionado las nuevas experiencias se conceptualizaban negativamente, como extravagancias, vulgaridad o chabacanería. Así, los indianos se transformaban en elementos pintorescos dentro de sus comarcas de origen, relacionados con mansiones con palmeras en el jardín, pero no con cotas significativas de experiencia o sabiduría adquirida. Esto creaba un estatus ambiguo en que el ascenso social producido por la riqueza se neutralizaba con la extranjerización asignada, de modo que el indiano no ascendía dentro de la escala de clases sociales local, sino que generaba un espacio propio pero diferente.

Si este proceso de exclusión del universo de lo reconocido como propio actuaba sistemáticamente con respecto a los emigrantes que retornaban (pese a que desde el punto de vista legal continuaban siendo ciudadanos de pleno derecho), incrementa su poder de segregación cuando se aplica a los retornados de segunda generación. En este caso, a la conceptualización excluyente se agrega una base legal. Ésta, al apoyarse en el ius sanguine puede ser superada en muchos casos por los inmigrantes latinoamericanos ${ }^{3}$, que suelen contar con algúr abuelo español (o del resto de la comunidad económica europea, lo que da iguales derechos). La segregación social, en cambio, se construye prescindiendo de la base legal, y ha acuñado en la útima década el neologismo "sudacan para señalar la condición de extranjería social de ese sector. Quedan así delimitados tres ámbitos de inclusión-exclusión: el legal, que se apoya en el derecho de sangre y brinda ciertas posibilidades a los latinoamericanos de obte-

3. Hasta 1985 la legislación española sólo concedía derecho a reclamat la nacionalidad a descendientes de españoles hombres, ya que se consideraba que las mujeres perdían su nacionalidad si se casaban con un extranjero y que, por consiguiente, no podían transmicirla a sus hijos. Esza discriminación de género se subsanó a partir de reclamaciones ante el tribunał constitucional. 
ner la ciudadanía; el cultural, marcado por semejanzas que facilitan la interacción, y el social, donde se establecen los límites de pertenencia. Ya Gordon ha señalado (hablando de EE.UU.) que las estructuras sociales son más significativas y persistentes que los contenidos culturales a efectos de diseñar los limites étnicos. Y Barth propone que la cercanía cultural no implica la desaparición, sino el desplazamiento de los límites de la estructura social a referentes simbólicos. Estos límites se activan o se neutralizan en la interacción social y, por consiguiente, en la escuela. En el caso que nos ocupa, es un ámbito de estudio interesante analizar cómo los límites construidos al respecto dif1cultan en la práctica la adopción por los niños y sus familias de las metas escolares, produciendo diftcultades en el proceso de escolarización.

\section{Bibliografía citada}

ABOU, Selim (1981). L'identité culturelle. Relations inter-ethniques et problemes d'aculturation. Editions Anthropos.

BARTH, Frederik (1976). Los grupos étnicos y sus fronteras. México: Fondo de Cultura Económica.

BASTIDE, Roger (1970). El prójimo y el extraño. Buenos Aires: Amorrortu.

BEAUVOIR, Simone de (1968). El segon sexe. Barcelona: Edicions 62, I952.

BENEDICT, Ruth (1971). «El hombre y la cultura». Biblioteca Fundamental del Hombre Moderno, núm. 1. Centro Editor de América Latina.

BUENO, Gustavo (1987). Etnologia y Utopia. Barcelona: Jucas Universidad, 1971.

CAMILLERI, Carmel (1992). "Cultura antropològica i de l'educación. Recerca i educacio interculturals (27 a 49) (Puig coord.). ERAIM. Barcelona: Hogar del Libro.

COI OMBRES, Adolfo (1992). «Modernidad y comunidad: una falsa dialectica». Voces y Culturas, núm. 4. Barcelona.

FinkielKRAUT, Alain (1987). La défaite de la Pensée. Paris: Gallimard.

GALviz, Juan M. (1987). "Juana Inés de La Cruz". Historia, núm. 16. Madrid: Quorum.

GORDON, Milton M. (1964). Assimilation in American Life. The Role of Race, Religion and National Origins. Nueva York: Oxford University Press.

GOSSELIN, Gabriel (1992). Une ethique des sciences sociales. La limite et l'urgence. Paris: L'Harmattan.

Gros, C. (1989). "Diffusion du savoir anthropologique et action humanitaire». Bulletin de l'Association Française des Anthropologues, núm. 37-38. París.

LLOBERA, Josep R. (1993). "Reconstructing Anthropology: the task for the nineties" en Después de Malinowski Bestard (Coord.). VI Congreso de Antropologia. Tenerife.

NEUFELD, María Rosa (1985). "Estrategias familiares y escuela». En $2^{\circ}$ Congreso Argentino de Antropología Social. Mecanografiado.

NogueIRA, Oracy (1954). «Preconceito Racial de Marca e Preconceito Racial de Origem". En Anais de Congreso Internacional de Americanistas. Sao Paulo.

PETRAS, James (1992), "Modernidad versus comunidad". Voces y culturas, núm. 2-3. Barcelona.

- (1992). "El imperialismo cultural a finales del siglo $\mathrm{XX}$ ". Voces $y$ culturas, núm. 4. Barcelona.

- (1993). "Arremeter contra molinos de viento, inventar adversarios". Voces y culturas, núm. S. Barcelona. 
PUJADAS, Juan J. (1993), «Racismo, xenofobia y conflicto étnico en una Europa en transiciónm. En Migraciones, segregación y racismo. PROVANSAZ (Coord.). VI Congreso de Antropología. Tenerife.

RicoeUR, P. (1990). Soi-même comme un autre. París: Le Seuil.

SIFFREDI, Alejandra y BRIONES de LANATA, Claudia (1989). "Discusión introductoria sobre los límites teóricos de lo étnicon. Antropologia y Economía. Cuadernos de Antropologia, núm. 3, p. 5-25. Buenos Aires: Universidad Nacional de Luján; Eudeba. 